\title{
Unmyelinated Tactile Cutaneous Nerves Signal Erotic Sensations
}

Emma H. Joensson, Helena Backlund Wasling, Vicktoria Wagnbeck, Menelaos Dimitriadis,
Janniko R. Georgiadis, Håkan Olausson and Ilona Croy

\section{Linköping University Post Print}

\section{Tweet}

N.B.: When citing this work, cite the original article.

Original Publication:

Emma H. Joensson, Helena Backlund Wasling, Vicktoria Wagnbeck, Menelaos Dimitriadis, Janniko R. Georgiadis, Håkan Olausson and Ilona Croy, Unmyelinated Tactile Cutaneous Nerves Signal Erotic Sensations, 2015, Journal of Sexual Medicine, (12), 6, 1338-1345.

http://dx.doi.org/10.1111/jsm.12905

Copyright: Wiley: 12 months http://eu.wiley.com/WileyCDA/

Postprint available at: Linköping University Electronic Press http://urn.kb.se/resolve?urn=urn:nbn:se:liu:diva-120062 


\section{Unmyelinated tactile cutaneous nerves signal erotic sensations}




\begin{abstract}

\section{Introduction}

Interpersonal touch is a powerful tool for communicating emotions and can among many things evoke feelings of eroticism and sexual arousal. The peripheral neural mechanisms of erotic touch signaling have been less studied. $\mathrm{C}$ tactile afferents (unmyelinated low threshold mechanoreceptors), known to underpin pleasant aspects of touch processing, have been posited to play an important role.
\end{abstract}

\title{
Method
}

In two studies we investigated the relationship between $\mathrm{C}$ tactile activation and the perception of erotic and pleasant touch, using tactile brushing stimulation. In total 66 healthy subjects ( 37 females, age range 19-51 years) were examined. In study one $(n=20)$ five different stroking velocities were applied to the forearm and the inner thigh. The participants answered questions about partnership, mood and touch. In study two $(n=46)$ the same five stroking velocities were applied to the forearm. The participants answered questions about partnership, touch and sexuality.

\section{Results}

Both touch eroticism and pleasantness were rated significantly higher for $\mathrm{C}$ tactile optimal velocities compared to sub-optimal velocities. No difference was found between the ratings of the thigh and the forearm. The velocity dependent rating curves of pleasantness, intensity and eroticism differed from each other. Pleasantness was best explained by a quadratic fit, intensity by a linear fit, and eroticism by both. A linear transformation of pleasantness and intensity predicted the observed eroticism ratings reliably. Eroticism ratings were negatively correlated with length of relationship.

\section{Conclusion}

Touch was rated most erotic when perceived as pleasant and weak. In human hairy skin, perception of pleasantness is correlated with the firing rate of $\mathrm{C}$ tactile afferents, and perception of intensity is correlated with the firing rate of $A \beta$ afferents. Accordingly, eroticism may be perceived most readily for touch stimuli that induce high activity in $C$ tactile fibers and low activity in $A \beta$ fibers.

\section{Key Words}

$\mathrm{C}$ tactile, touch, erotic, somatosensory, pleasantness, periphery 


\section{Introduction}

Touch, delivered in the right way, by the right person and under the right circumstances can be a powerful sexual incentive, i.e. it can elicit motivated behaviour aimed at sexual activity, or feelings of sexual desire, arousal or pleasure. Such 'erotic touch' include for example caressing, massaging and static touch(1). Conversely, dysfunctional or altered touch perception is associated with sexual problems like hyposexual desire disorder(2).Yet, despite the beneficial effects of erotic touch and bodily intimacy on relationship quality and individual happiness(1) it is still largely unknown how somatosensory stimuli may give rise to sexual feelings.

Touch is communicated through mechanoafferents in the peripheral nervous system that innervates the skin. These divide into two large groups: myelinated, fast conducting A fibers and unmyelinated, slowly conducting $\mathrm{C}$ tactile fibres. $\mathrm{C}$ tactile fibers, a subgroup of the $\mathrm{C}$ fibers, are found only in hairy skin and respond optimally to slow stroking stimulation with a velocity of $1-10 \mathrm{~cm} / \mathrm{s}$, to light force, and to temperatures of about $32^{\circ} \mathrm{C}-$ a stimulation that resembles interpersonal touch(3-6). Additionally, $\mathrm{C}$ tactile firing correlates highly with subjective pleasantness ratings of touch. This has led to the "social touch hypothesis", stating that C tactile fibers are specifically tuned to respond to comforting interpersonal touch(4). Interpersonal touch has the ability to communicate a wide range of emotions, from disgust to love(7).

In addition to pleasant or social touch, $\mathrm{C}$ tactile fibers are suggested to be mediators of erotic touch(8). This idea is to some extent supported by observations in patients who are relieved from excruciating chronic pain by surgical transection of the spinothalamic tract (anterolateral cordotomy (9). Postoperatively, these patients report no erotic cutaneous sensation on the lesioned side(9). Since C tactile fibers probably projects together with the nociceptors and thus are affected by the transection, this suggests that $\mathrm{C}$ tactile signaling is necessary for erotic touch sensation. However, the potential involvement of $\mathrm{C}$ tactile afferents in erotic touch perception has, to the best of our knowledge, not been specifically examined. The aim of this study was to investigate a potential correlation between stimulation of $\mathrm{C}$ tactile fibers and erotic perception.

If $\mathrm{C}$ tactile fibers are involved in the peripheral coding of somatosensory sexual incentives, $\mathrm{C}$ tactile optimal stroking touch with a velocity of $1-10 \mathrm{~cm} / \mathrm{s}$ is expected to be perceived as more erotic compared to $\mathrm{C}$ tactile suboptimal touch. This hypothesis was tested in two studies. Study one compared eroticism ratings of $\mathrm{C}$ tactile optimal $(1,3$ and $10 \mathrm{~cm} / \mathrm{s})$ and suboptimal brushing $(0.3$ and $30 \mathrm{~cm} / \mathrm{s})$ on two body sites (forearm and inner thigh). Study two aimed to replicate the results from study one on the forearm and additionally tested if eroticism ratings to $\mathrm{C}$ tactile optimal brushing are related to sexual behavior in daily life. The forearm was chosen based on previous studies on $\mathrm{C}$ tactile related perception $(3,10,11)$, and the inner thigh was chosen based on high self-rated erotic touch perception(12). 


\begin{abstract}
Aim
We aimed to investigate the relationship between $\mathrm{C}$ tactile afferent stimulation and erotic touch perception in healthy adults.

\section{Main outcome measures}

Ratings of eroticism, pleasantness, and intensity of touch stimuli of different velocities were obtained from all participants.
\end{abstract}

\title{
Study 1
}

\section{Methods}

\section{Ethical declaration}

The investigations were performed according to the Declaration of Helsinki on Biomedical Research Involving Human Subjects. The protocol was approved by the ethics committee in Gothenburg, Sweden. Following explanation of the study, written informed consent was obtained from all participants.

\section{Participants}

Twenty healthy volunteers (age 19-33 years (mean 23.5 +/-3.2 years SD), 10 females) participated. Most of them were undergraduate students and considered themselves to be healthy. The volunteers were paid for participation.

\section{Procedure}

\section{Questionnaires}

The participants answered the Multidimensional Mood State Questionnaire (MDMQ (13)) and the Social Touch Questionnaire (STQ (14))(both translated to Swedish) before starting the experiment. The MDMQ consists of 30 items asking about current mood on the dimensions good-bad, awake-tired and calm-nervous. The STQ consists of 20 items asking about attitudes towards interpersonal touch.

\section{Presentation of touch stimuli}

Two skin sites were stimulated; the left inner thigh and the left dorsal forearm. The participants wore shorts and were seated in a comfortable chair in front of a computer screen with their left arm in prone position on a pillow. The touch stimuli were applied by a custom-built robotic device (rotary tactile stimulator, RTS; Dancer Design, St Helens, UK), using a $50 \mathrm{~mm}$ wide, flat soft watercolor brush made of fine, smooth goat's hair. The robotic device was controlled through LabVIEW (National Instruments, Austin, TX, USA). The touch was applied as stroking stimuli in proximal to distal direction on a section of skin of about $6.5 \mathrm{~cm}$ with a vertical force of $0.4 \mathrm{~N}$. Five different stroking velocities were used; C 
tactile optimal touch with a velocity of 1,3 and $10 \mathrm{~cm} / \mathrm{s}$ and $\mathrm{C}$ tactile suboptimal touch with a velocity of 0.3 and $30 \mathrm{~cm} / \mathrm{s}(3)$.

Each participant received 15 stimulations per skin site ( 5 velocities $* 3$ repetitions). Presentation order of stimuli and testing order of skin site were randomized. After each presentation, eroticism (0 to 20; not erotic at all to extremely erotic), pleasantness (-10 to 10; extremely unpleasant to extremely pleasant), and intensity ( 0 to 20 ; not intense at all to extremely intensive) of the touch stimuli were rated on visual analogue scales (VASs) presented on a computer screen. No further information about the interpretation of any of the anchor labels on the VASs was given. In order to focus on the perception of touch, the participants wore goggles that inhibited peripheral vision. Participants were acoustically shielded from the noise of the RTS by pink noise through headphones.

Great care was exercised in order to make the participants comfortable with the environment. While filling out the questionnaires the participants were in the experimental room and wore shorts in order to get familiarized with the testing situation. The participants were assured that the experimenter would not follow their ratings and that all collected data was stored anonymously.

\section{Tactile sensitivity}

In the last part of the experiment, tactile sensitivity was measured on the left dorsal forearm and on the left inner thigh. Tactile sensitivity was included to examine possible differences in discriminatory capacity between the forearm and the inner thigh. The monofilament test $(15,16)$ was used in a staircase method (17), where one out of 10 single filaments (ranging from $0.08 \mathrm{mN}$ to $30 \mathrm{mN}$ ) was applied to the skin twice. The test always started with the strongest filament. If the participant perceived both stimuli, the testing continued with the next weaker filament in the series. Otherwise testing continued with the next stronger filament. The testing continued for six turning points (change from stronger to weaker filament or vice versa); the average of the last four turning points was used as threshold (compare (18)). Participants were prevented from seeing the stimulation.

\section{Statistical analysis}

Statistical analyses were performed using SPSS version 22 (IBM, Chicago, USA). VAS data was averaged across the three repetitions of each velocity, and ratings of eroticism, pleasantness, and intensity were analyzed separately in a repeated measurement ANOVA with velocities (five) and skin site (two) as within subject factors, and Greenhouse-Geisser correction was applied. Ratings of eroticism, pleasantness and intensity were correlated with the outcome scores from the mood questionnaire and the social touch questionnaire (Pearson correlation). Bonferroni-correction was applied (factor three). Tactile sensitivity of skin sites was compared with paired t-test. Level of significance was set to 0.05 . 


\section{Results}

There was a significant main effect of velocity $(F[4,16]=6.2, p=0.003)$ on the eroticism ratings. The relation between velocity and eroticism ratings was best described by a quadratic fit $(F[1,19]=12.9$, $\mathrm{p}=0.002)$, and in tendency by linear fit $(\mathrm{F}[1,19]=4.3, \mathrm{p}=0.052)$. Eroticism ratings were highest for the slower $\mathrm{C}$ tactile optimal velocities of 1 and $3 \mathrm{~cm} / \mathrm{s}$ (Fig 1). There was no significant main effect of skin site $(F[1,19]=2.5)$ or for the interaction between skin site and velocity $(F[4,16]=0.4)$. Post hoc testing was performed on combined forearm and thigh data and showed significantly higher ratings of eroticism for the $\mathrm{C}$ tactile optimal velocities of 1 and $3 \mathrm{~cm} / \mathrm{s}$ compared to the suboptimal velocities of 0.3 and 30 $\mathrm{cm} / \mathrm{s}$ ( $\mathrm{p}$ values ranging from 0.001 to 0.04 ). There were no significant differences of eroticism ratings between velocities of $0.3,10$, and $30 \mathrm{~cm} / \mathrm{s}$. For pleasantness ratings, there was a significant main effect of velocity $(\mathrm{F}[4,16]=9.2, \mathrm{p}<0.001)$, and the relation between velocity and pleasantness was best described by a quadratic fit $(\mathrm{F}[1,19]=18.2, \mathrm{p}<0.001)$. For intensity ratings, there was a significant main effect of velocity $(\mathrm{F}[4,16]=4.5, \mathrm{p}=.024)$. However, the relation was best described by a linear $(\mathrm{F}[1,19]=5.7, \mathrm{p}=.028)$, instead of a quadratic fit.

Ratings of eroticism were neither significantly correlated with the outcome from the social touch questionnaire (STQ) ( $\mathrm{r}=0.03$ ) nor with the good/bad mood and calm/nervous subscales from the Multidimensional Mood State Questionnaire (MDMQ) ( $\mathrm{r}=0.01-0.10)$. The highest, but still nonsignificant, correlation was obtained with the tired/awake subscale $(r=0.33, p=0.16)$.

Comparison of skin sites for tactile discrimination revealed a significantly lower sensitivity of the inner thigh compared to the forearm $(\mathrm{t}=3.5, \mathrm{p}=0.002)$. The mean force for tactile discrimination was $0.16 \mathrm{mN}(+/-0.13 \mathrm{mN} \mathrm{SD})$ on the forearm and $0.67 \mathrm{mN}(+/-0.68 \mathrm{mN} \mathrm{SD})$ on the inner thigh.

\section{Study 2}

\section{Methods}

\section{Ethical declaration}

The investigations were performed according to the Declaration of Helsinki on Biomedical Research Involving Human Subjects. The protocol was approved by the central ethics committee in Gothenburg, Sweden. Following explanation of the study, written informed consent was obtained from all participants.

\section{Participants}

46 healthy volunteers (age 19-51 years (mean 26.6 +/-6.8 years SD), 27 female) participated. 29 of the participants reported to be in a relationship ( 25 heterosexual; mean duration of relationship $2.7+/-2.7$ 
years SD). Most of them were undergraduate students, and considered themselves to be healthy. None of them participated in study one. The volunteers were paid for participation.

\section{Procedure}

\section{Questionnaires}

The participants answered the STQ (14) and questions about touch and sexuality in daily life. Participants were asked about "how often do you have intimate body contact with family members or friends? (more than 1h/day, more than 10min/day, ones/day, more than once/week, once/week, once/month, never)" and "how much do you appreciate this type of body contact? (Very much, much, neither or, not very much, not at all)". Intimate body contact refers to both sexually motivated touch and activities such as hugging or cuddling. Additional questions about sexuality were "If you have a partner, how often would you like to be sexually active with him/her?" and "How often are you sexually active with your partner? (never, once/month or less, once a week, more than once/week, once/day or more)". Participants additionally answered the Erogenous Zone Questionnaire (EZQ), which asks about the level of sexual arousal following touch in a variety of body parts on a visual analogue scale ranging from 0 to 10 (12). The questionnaire was translated to Swedish, implemented in MATLAB (MathWorks, Natick, MA, USA), and presented on a screen. All forms were filled out before starting the experiment, except for the Erogenous Zone Questionnaire, which was answered after the experiment.

\section{Presentation of touch}

The experiment was conducted in the same way as in study one. However, brushing was only performed on the left dorsal forearm as no difference had been observed between ratings from forearm and thigh in study one.

\section{Statistical analysis}

Statistical analyses were performed using SPSS version 22 (IBM, Chicago, USA). Touch rating data was analyzed similar to study one. The larger number of participants additionally enabled analysis of gender differences.

The averaged overall eroticism rating was correlated to the total score of the STQ and the EZQ questionnaires and to the outcome of the questions about sexuality and touch (Pearson correlations).

Shapes of the curves of pleasantness and eroticism rating were compared. Therefore, rating data was combined with the rating data from the forearm of study 1 , which was collected in a similar manner. This approach led to a sample size of 67 people. A repeated measurement ANOVA was calculated with the within subject factors velocity (five) and rating scale (three). Furthermore, regression analysis was 
performed in order to clarify, whether velocity dependent rating curves followed a quadratic or linear fit.

\section{Results}

Resembling the results from study one, there was a significant main effect of velocity $(F[4,42]=10.2$, $\mathrm{p}<0.001)$ on eroticism ratings, and the relation was best described by a quadratic $(\mathrm{F}[1,45]=13.2$, $\mathrm{p}=0.001)$ and a linear fit $(\mathrm{F}[1,45]=11.9, \mathrm{p}=0.001)$. The highest ratings were given in the $\mathrm{C}$ tactile optimal range and the slow velocity of $1 \mathrm{~cm} / \mathrm{s}$ was rated most erotic (Figure 1). Post hoc-tests revealed that the $\mathrm{C}$ tactile optimal velocities of 1,3 and $10 \mathrm{~cm} / \mathrm{s}$ were rated as significantly more erotic than the suboptimal $30 \mathrm{~cm} / \mathrm{s}$ (each $\mathrm{p}<0.001$ ), and $1 \mathrm{~cm} / \mathrm{s}$ was rated significantly more erotic compared to the suboptimal $0.3 \mathrm{~cm} / \mathrm{s}(\mathrm{p}=0.04)$. There was no significant difference in erotic perception of brushing with $3,10 \mathrm{~cm} / \mathrm{s}$ or the suboptimal $0.3 \mathrm{~cm} / \mathrm{s}$. For ratings of pleasantness and intensity as well, a significant main effect of velocity was obtained $(F[4,42]=11.9, p<0.001$ and $F[4,42]=7.6, p<0.001$, respectively). For pleasantness, the relation was best described by a quadratic fit $(F[1,45]=42.2, p<0.001)$, whereas the relation with intensity was best described by a linear fit $(\mathrm{F}[1,45]=10.7, \mathrm{p}=0.002)$.

Women rated touch more erotic compared to men $(F[1,44]=7.4, p=0.009)$. The interaction between sex and velocity was not significant $(\mathrm{F}=2.3)$. For pleasantness and intensity ratings there were no significant main effects of sex (pleasantness ratings $F[1,44]=3.7$; intensity ratings $F[1,44]=3.8$ ). Questionnaire data and coherence with $\mathrm{C}$ tactile eroticism ratings

The majority of the participants (56\%) reported to have intimate body contact with family members or friends at least once a day. $60 \%$ of the participants reported to appreciate this type of touch "very much" and none answered "not very much" or "not at all". There was a significant positive correlation between the frequency of intimate body contact and the appreciation of such contact $(r=0.49, p=0.001)$. However, there was no correlation between the frequency or appreciation of intimate body contact with the eroticism ratings.

Of those 40 participants, who reported to be or have been sexually active, $86.6 \%$ stated that they wanted to be sexually active several times a week, but only $40 \%$ actually were. Instead the most common answer on sexual activity frequency was about once a week (56.7\%). There was a significant positive correlation between the mean eroticism ratings and frequency of sexual activity $(r=0.39, p=0.035)$, but not with the desire for sexual activity. There was a significant negative correlation between the duration of relationship and the amount of sexual activity $\left(\mathrm{r}_{\mathrm{s}}=-0.63, \mathrm{p}<0.001\right)$. Consistently, there was a significant negative correlation between the duration of relationship and the overall rating of eroticism $(r=-.44$, $\mathrm{p}=0.02$ ). The longer participants were in a relationship, the less erotic they perceived touch. Importantly, 
this result remained stable, if controlling for age of the participants (partial correlation: $\mathrm{r}=-0.38$, $\mathrm{p}=0.046)$.

As in study one, the overall score of the STQ was not correlated to the eroticism ratings $(r=-0.06)$. However, there was a significant positive correlation between the scores of the EZQ and the overall eroticism rating $(\mathrm{r}=0.30, \mathrm{p}=0.04)$. The inner thigh was rated as significantly more sexually arousing than the forearm (thigh mean=7.68, $\mathrm{SD}=2.01$; forearm mean=3.32, $\mathrm{SD}=3.33$ ), $\mathrm{t}(46)=-8.386, \mathrm{p}<0.001$ ).

In the sample four people reported no sexual experience. Three of them still rated touch as erotic, whereas one participant did not. These participants could potentially be asexual, especially the participant who did not find any touch erotic. However, removing the four participants from the analysis did not change the results.

\section{Comparison between eroticism, pleasantness and intensity ratings}

For comparing the results from the different rating scales, the data from study 1 and study 2 were combined. There was a significant interaction effect between velocity and rating scales, implying that the curves of pleasantness, intensity and eroticism differed from each other $(F[8,58]=18.2, p<0.001)$. Velocity dependent rating curves of pleasantness were best explained by a quadratic fit $\left(R^{2}=0.133\right.$, $\mathrm{F}=25.1, \mathrm{p}<0.001)$, intensity ratings by linear fit $\left(\mathrm{R}^{2}=0.053, \mathrm{~F}=18.2, \mathrm{p}<0.001\right)$, and eroticism ratings were best explained by both, linear $\left(\mathrm{R}^{2}=0.044, \mathrm{~F}=14.9, \mathrm{p}<0.001\right)$ and quadratic fits $\left(\mathrm{R}^{2}=0.084, \mathrm{~F}=15.0\right.$, $\mathrm{p}<0.001)$. We therefore tested, whether a combination of pleasantness and intensity could explain eroticism ratings. In fact, a linear transformation of pleasantness and intensity $\left(1.5^{*}\right.$ pleasantness intensity) predicted the observed eroticism ratings in a way that no differences between predicted and observed eroticism ratings were statistically detectable in any of the five velocities (for each velocity: $\mathrm{t}=0.1$ to $0.8 ; \mathrm{p}=0.4$ to 0.9$)$.

\section{Discussion}

We hypothesized that $\mathrm{C}$ tactile afferents influence the perception of eroticism. $\mathrm{C}$ tactile afferents have previously been found to mediate pleasant touch and respond optimally to slow stroking touch (stroking velocities $1-10 \mathrm{~cm} / \mathrm{s}$ ) (3). In the present study, the highest eroticism as well as pleasantness ratings were found for brush stroking with velocities optimally activating $\mathrm{C}$ tactile afferents. Our interpretation of these results is that $\mathrm{C}$ tactile afferents are involved in the signaling of not only pleasant but also erotic stimuli.

Interestingly, ratings of pleasantness and eroticism showed different velocity dependence with eroticism ratings being higher at slow stroking velocities. Our analysis suggests that this effect is explained by the combined ratings of pleasantness and intensity. The combination of both ratings 
showed that stimuli were perceived most erotic when high on pleasantness but low on intensity. Ratings of pleasantness can be seen as a proximate for $\mathrm{C}$ tactile stimulation; while ratings of intensity follow involvement of $A \beta$ fibers(3). Accordingly, eroticism may be perceived for touch stimuli that are optimal in activating $C$ tactile fibers and activate $A \beta$ fibers in the lower end of their firing potential.

The forearm EZQ score was found to be significantly lower than that of the inner thigh, confirming previous results(12). However, this difference was not detected in the eroticism or pleasantness ratings following tactile stimulation. People rate the inner thigh more erotic compared to the forearm, when asked in a questionnaire, but not when actually exposed to stimulation. There is no human data on innervation densities of $\mathrm{C}$ tactile afferents across different hairy skin areas and previous work investigating the pleasantness-to-touch of different materials found no significant difference between the touch pleasantness ratings for the thigh and the forearm(19). Further studies on human $\mathrm{C}$ tactile density across body sites are warranted.

C tactile stimulation should not be seen as determining erotic perception, but rather as creating an emotional platform - or background - that increases the likelihood of sexual feelings. It is therefore important to consider the role of other factors, like context. It has previously been shown that context impacts the overall pleasantness percept(20). For eroticism ratings, a negative correlation was found with the length of the relationship which might reflect the multidimensionality of erotic touch perception. Touch can have several impacts on partners, for example physical affection has been found to be very important for relationship satisfaction (21), and cuddling seems to be important for the level of sexual activity(22). It is possible that the meaning of touch is gradually shifted in the course of a relationship. When creating a romantic partner bond, touch may be sensed as more erotic, whereas touch in an established relationship might evoke feelings of security and affiliation, that help maintaining the bond (23). In line with this interpretation, we found that established couples were less sexually active compared to more recently formed couples.

It is possible that the participants had different interpretations of the word erotic during the rating procedure, which potentially could be a limitation of the studies. However, none of the participants asked about the meaning of the word, and by not defining it, the participants rated according to their interpretation of the word erotic.

In addition to a strong contribution from $\mathrm{C}$ tactile afferents inputs from all mechanoreceptors are likely to be integrated, shaping the experience of erotic touch. There are a few reported cases of patients suffering from loss of all myelinated nerves in the periphery but sparing of the unmyelinated afferents 
(sensory ganglionpathy; see e.g. (24-26)). However, to our knowledge there has been no published data on erotic touch or sexual function disturbances in these patients.

The present results suggest a relationship between moving touch, $\mathrm{C}$ tactile afferents and eroticism, which begs the question if a similar relationship is present for the skin of the genitalia. The genital area generally has the highest erotogenic potential, but whether $\mathrm{C}$ tactile afferents exist here is unknown. The genital area has both hairy and glabrous skin, and $\mathrm{C}$ tactile afferents would be expected to be present in hairy skin only since they are associated with hair follicles (27). Nevertheless, the glabrous skin of the glans penis and glans clitoris contains a high density of unmyelinated fibers $(28,29)$, the function of which is still subject to speculation (see e.g. $(29,30)$ ). Whether the apparent erotogenic potential of C tactile stimulation has implications for understanding sexual dysfunctions characterized by altered erotic perception or genital function, like premature and delayed ejaculation, erectile dysfunction or persistent genital arousal disorder, might fuel future research questions. In summary, the present study shows, for the first time, that $\mathrm{C}$-tactile afferents bear the potential of underpinning perception of eroticism. 
1. Galinsky AM. Sexual touching and difficulties with sexual arousal and orgasm among U.S. older adults. Arch Sex Behav. 2012 Aug;41(4):875-90.

2. Frohlich PF, Meston CM. Tactile sensitivity in women with sexual arousal disorder. Arch Sex Behav. 2005 Apr;34(2):207-17.

3. Löken LS, Wessberg J, Morrison I, McGlone F, Olausson H. Coding of pleasant touch by unmyelinated afferents in humans. Nat Neurosci. 2009;12(5):547-8.

4. Olausson H, Wessberg J, Morrison I, McGlone F, Vallbo A. The neurophysiology of unmyelinated tactile afferents. Neurosci Biobehav Rev. Elsevier; 2010;34(2):185-91.

5. Ackerley R, Backlund Wasling H, Liljencrantz J, Olausson H, Johnson RD, Wessberg J. Human C-tactile afferents are tuned to the temperature of a skin-stroking caress. J Neurosci. 2014 Feb 19;34(8):2879-83.

6. McGlone F, Wessberg J, Olausson H. Discriminative and Affective Touch: Sensing and Feeling. Neuron. Elsevier; 2014 May;82(4):737-55.

7. Hertenstein MJ, Keltner D, App B, Bulleit BA, Jaskolka AR. Touch communicates distinict emotions. Emotion. 2006;6:528-33.

8. Kandel ER, Schwartz JH, Jessell TM, Siegelbaum SA, Hudspeth AJ. Principles of Neural Science, Fifth Edition. fifth edit. McGraw Hill; 2013.

9. Lahuerta J, Bowsher D, Campbell J, Lipton S. Clinical and instrumental evaluation of sensory function before and after percutaneous anterolateral cordotomy at cervical level in man. Pain. $1990 \mathrm{Jul} ; 42(1): 23-30$.

10. May AC, Stewart JL, Tapert SF, Paulus MP. The effect of age on neural processing of pleasant soft touch stimuli. Front Behav Neurosci. 2014 Jan;8(February):52.

11. Triscoli C, Olausson H, Sailer U, Ignell H, Croy I. CT-optimized skin stroking delivered by hand or robot is comparable. Front Behav Neurosci. 2013 Jan;7:208.

12. Turnbull OH, Lovett VE, Chaldecott J, Lucas MD. Reports of intimate touch: erogenous zones and somatosensory cortical organization. Cortex. 2014 Apr;53:146-54.

13. Steyer R, Schwenkmezger P, Notz P, Eid M. Der Mehrdimensionale Befindlichkeitsfragebogen (MDBF). Göttingen: Hogrefe; 1997.

14. Wilhelm FH, Kochar AS, Roth WT, Gross JJ. Social anxiety and response to touch: incongruence between self-evaluative and physiological reactions. Biol Psychol. 2001 Dec;58(3):181-202.

15. Ackerley R, Carlsson I, Wester H, Olausson H, Backlund Wasling H. Touch perceptions across skin sites: differences between sensitivity, direction discrimination and pleasantness. Front Behav Neurosci. Frontiers; 2014 Jan 19;8:54.

16. Backlund H, Morin C, Ptito A, Bushnell MC, Olausson H. Tactile functions after cerebral hemispherectomy. Neuropsychologia. 2005 Jan;43(3):332-9.

17. Sweetcorn TN. The Staircase-Method in Psycophysics. Am J Psychol. 1962;75(3):485-91. 
18. Kobal G, Hummel T, Sekinger B, Barz S, Roscher S, Wolf S. "Sniffin' sticks": screening of olfactory performance. Rhinology. 1996 Dec;34(4):222-6.

19. Essick GK, McGlone F, Dancer C, Fabricant D, Ragin Y, Phillips N, et al. Quantitative assessment of pleasant touch. Neurosci Biobehav Rev. 2010 Feb;34(2):192-203.

20. Croy I, Angelo S D', Olausson H. Reduced pleasant touch appraisal in the presence of a disgusting odor. PLoS One. 2014 Jan;9(3):e92975.

21. Gulledge AK, Gulledge MH, Stahmannn RF. Romantic Physical Affection Types and Relationship Satisfaction. Am J Fam Ther. Routledge; 2003 Jul;31(4):233-42.

22. Van Anders SM, Edelstein RS, Wade RM, Samples-Steele CR. Descriptive experiences and sexual vs. nurturant aspects of cuddling between adult romantic partners. Arch Sex Behav. 2013 May;42(4):553-60.

23. Brennan $\mathrm{KA}, \mathrm{Wu} \mathrm{S}$, Loev J. Adult romantic attachment and individual differences in attitudes toward physical contact in the contex of adult romantic relationships. In: Simpson JA, Rhodes WS, editors. Attachment theory and close relationships. New York: Guilford Press; 1998. p. 394-428.

24. Čeko M, Seminowicz D a, Bushnell MC, Olausson HW. Anatomical and functional enhancements of the insula after loss of large primary somatosensory fibers. Cereb Cortex. 2013 Sep;23(9):2017-24.

25. Olausson H, Lamarre Y, Backlund H, Morin C, Wallin BG, Starck G, et al. Unmyelinated tactile afferents signal touch and project to insular cortex. Nat Neurosci. Nature Publishing Group; 2002 Sep;5(9):900-4.

26. Cole J. Pride and a Daily Marathon. MIT Press; 1995.

27. Abraira VE, Ginty DD. The Sensory Neurons of Touch. Neuron. 2013;79(4):618-39.

28. Halata Z, Munger BL. The neuroanatomical basis for the protopathic sensibility of the human glans penis. Brain Res. 1986 Apr;371(2):205-30.

29. Shih C, Cold CJ, Yang CC. Cutaneous corpuscular receptors of the human glans clitoris: descriptive characteristics and comparison with the glans penis. J Sex Med. 2013 Jul;10(7):1783-9.

30. Johnson RD, Kitchell RL. Mechanoreceptor response to mechanical and thermal stimuli in the glans penis of the dog. J Neurophysiol. 1987 Jun 1;57(6):1813-36. 


\section{Figures}

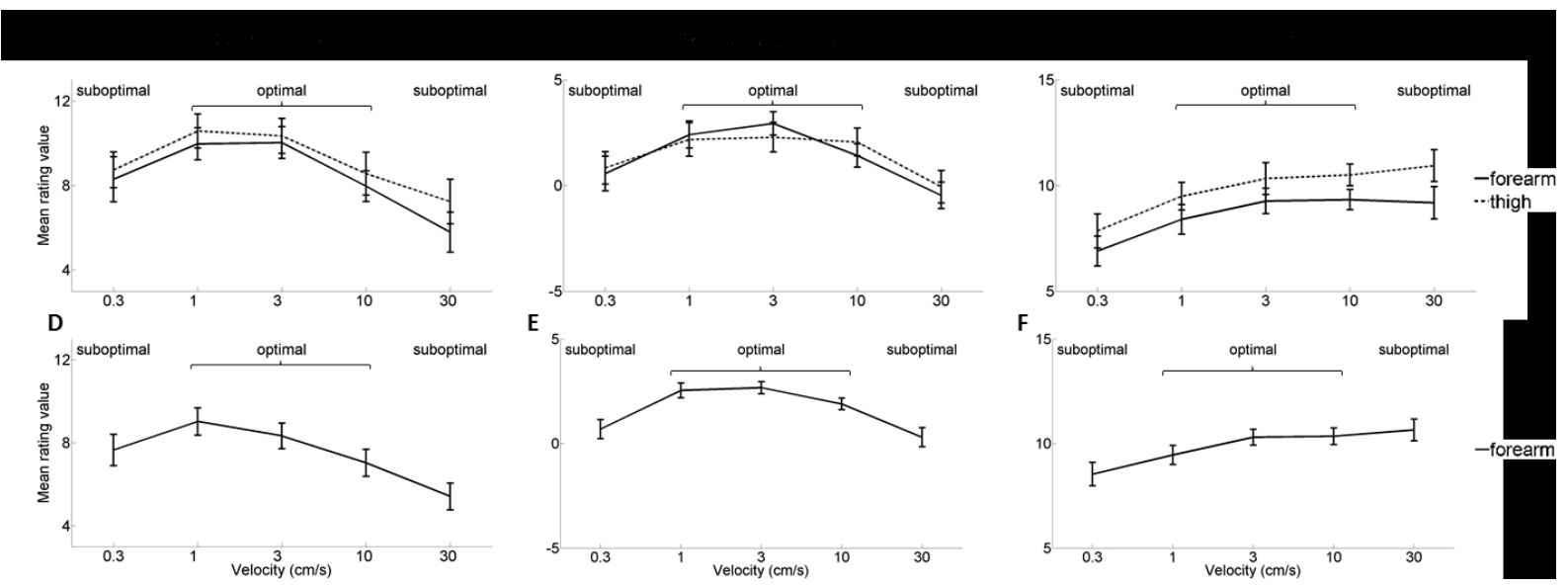

Figure 1: Results of the VAS ratings. Each graph shows the dependence of the ratings of eroticism, pleasantness or intensity for the five different velocities used. The top row (A-C) shows the results from Study one, where the ratings for stimulation of the forearm is in solid and the ratings for the thigh touch is in dashed. For study two (bottom row, D-F), the forearm only was stimulated. For the eroticism and pleasantness an inverted $U$ shape can be seen for the ratings as function of the velocities, which is not present for ratings of intensity. Please note that the y-axis have been cropped to give the best display of the velocity dependent shape of curves. Also note that the ratings were done of different scales (eroticism and intesnity $0-20$, pleansantness -10 10) The distance of the scales is equal for all ratings. Error bars display the standard error of the mean (SEM).

\section{Acknowledgements}

This work was supported by a grant from the German Research Foundation to IC (DFG; CR 479/1-1), and by a grant from the Swedish Research Council to HO. The funding sources had no involvement in collection, analysis and interpretation of data; in the writing of the report; or in the decision to submit the article for publication. 